\begin{tabular}{|c|c|c|c|}
\hline Demographic & $\begin{array}{l}\text { Preemptive } \\
\text { multimodal } \\
\text { analgesia group } \\
(n=40)\end{array}$ & $\begin{array}{l}\text { Control group } \\
(n=40)\end{array}$ & $P$ value \\
\hline Age & $67.9 \pm 7.6$ & $66.3 \pm 10.0$ & $0.417^{\prime \prime}$ \\
\hline BMD & $-1.9 \pm 1.3$ & $-2.5 \pm 0.9$ & $0.107^{\prime \prime}$ \\
\hline $\begin{array}{l}\text { Intraoperative blood } \\
\text { loss }\end{array}$ & $383.0 \pm 89.4$ & $400.3 \pm 84.9$ & $0.379^{\prime \prime}$ \\
\hline $\begin{array}{l}\text { Postoperative } \\
\text { Hemovac drain } \\
\text { output }\end{array}$ & $276.5 \pm 111.1$ & $289.3 \pm 149.1$ & $0.335^{\prime \prime}$ \\
\hline Nonunion (cases) & 3 & 4 & $0.692^{*}$ \\
\hline
\end{tabular}

Abstract 90 Table 2
\begin{tabular}{llll}
\hline $\begin{array}{l}\text { Post-op } \\
\text { day }\end{array}$ & $\begin{array}{l}\text { Preemptive multimodal } \\
\text { analgesia group }(n=40)\end{array}$ & $\begin{array}{l}\text { Control group } \\
(n=40)\end{array}$ & $P$ value \\
\hline $\begin{array}{l}\text { Recovery } \\
\text { room }\end{array}$ & $5.90 \pm 1.10$ & $7.12 \pm 1.13$ & 0.000 \\
After 8 h & $5.47 \pm 1.17$ & $6.75 \pm 1.12$ & 0.000 \\
Day 1 & $4.25 \pm 0.89$ & $5.52 \pm 1.06$ & 0.000 \\
Day 2 & $3.62 \pm 0.92$ & $5.12 \pm 1.13$ & 0.000 \\
Day 4 & $3.10 \pm 0.92$ & $4.52 \pm 0.96$ & 0.000 \\
Day 7 & $2.22 \pm 0.69$ & $3.65 \pm 1.29$ & 0.000 \\
\hline
\end{tabular}

Conclusions **The new preemptive multimodal analgesic combination is safe and effective postoperative.

**may reduce severity of adverse effects of the opioid.

$*$ Regular review, follow up of patients postoperative by APS team for 4 days is mandatory.

\section{HAS COVID CHANGED THE PERCEPTION ABOUT REGIONAL ANAESTHESIA? - A SURVEY AMONG PATIENTS, ANAESTHETISTS AND SURGEONS- A SINGLE CENTRE SPECIALIST ORTHOPAEDIC HOSPITAL STUDY}

S Dsouza*, M Paz Sebastian, A Sell, S Shanmuganathan, J McGrath. Royal National Orthopaedic Hospital, London, UK

10.1136/rapm-2021-ESRA.91

Background and Aims The COVID-19 pandemic brought an increase in the use of regional anaesthesia (RA) in an effort to avoid aerosol generating procedures. We conducted a survey among patients, anaesthetists and orthopaedic surgeons to find their views about RA during and after the pandemic and whether the pandemic has changed their perception about RA.

Methods A 7 question survey (figure 1) regarding preferences of anaesthetic technique and satisfaction was filled by patients who had surgery under RA during the pandemic, anaesthetists and surgeons in a single specialist Orthopaedic centre.

Results We got responses from 147 patients,25 surgeons and 32 anaesthetists. Overall, the RA preference among patients increased from $43.53 \%$ to $85 \%$, among surgeons from $28 \%$ to $56 \%$ and from $75 \%$ to $78.12 \%$ among anaesthetists (figure 2,3). RA acceptance increased by $24 \%$ among patients with previous surgical experience under RA, and 52\% among patients with no prior experience. The highest increase was seen after blocks followed by spinal \pm blocks. The main reasons for RA scepticism among patients were anxiety about being awake and feeling pain, tendency to leave it to the patient decision and unpredictable success of RA among surgeons and anaesthetists.

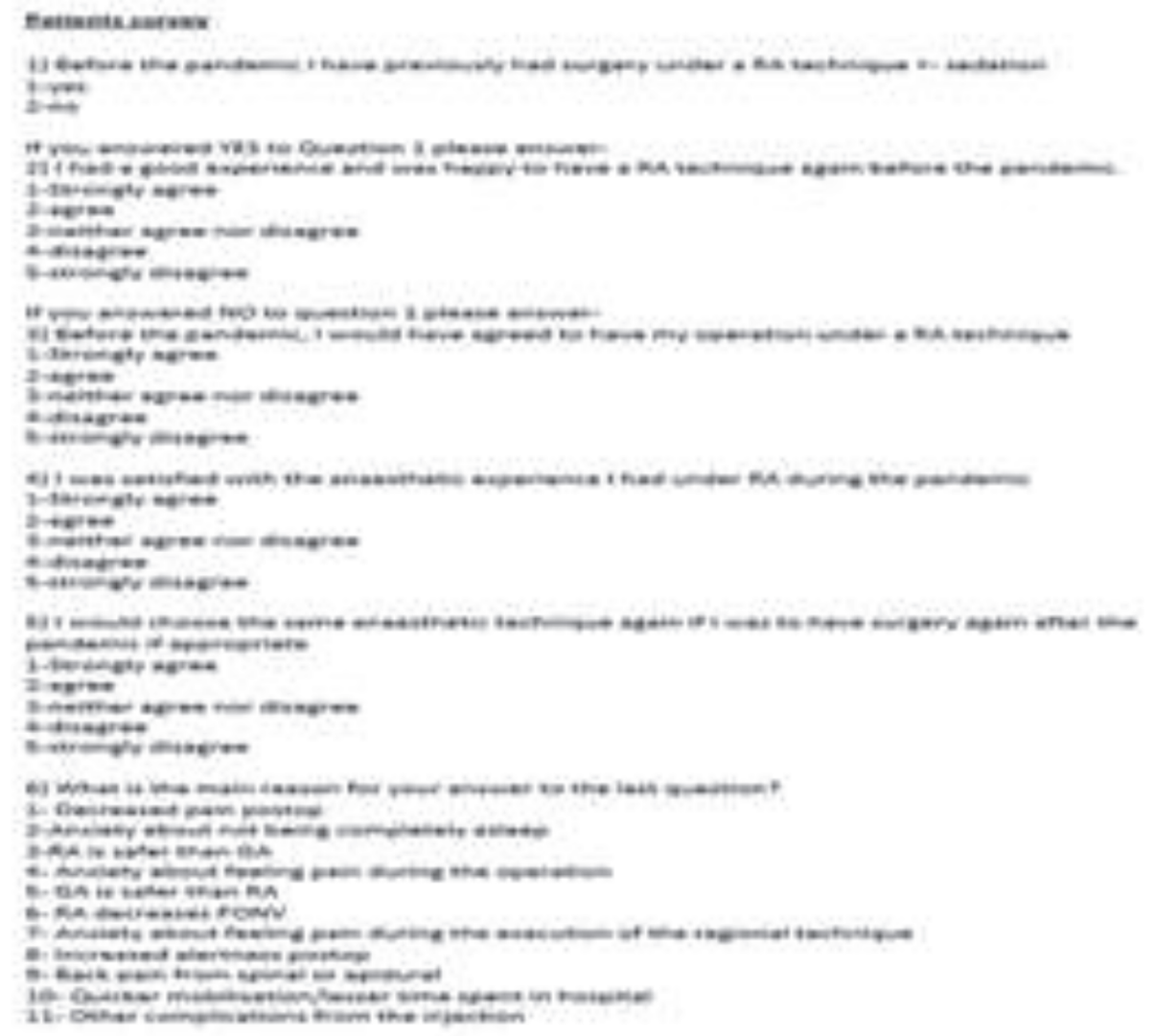




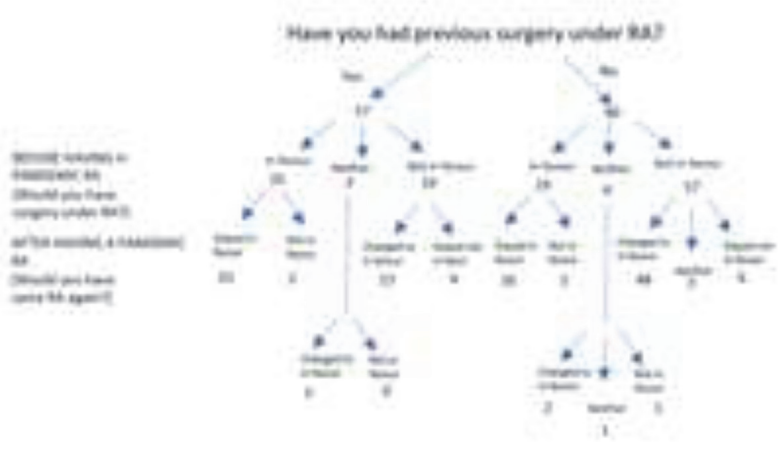

Abstract 91 Figure 2 Overall changes in patient responses before and after having a RA during the pandemic

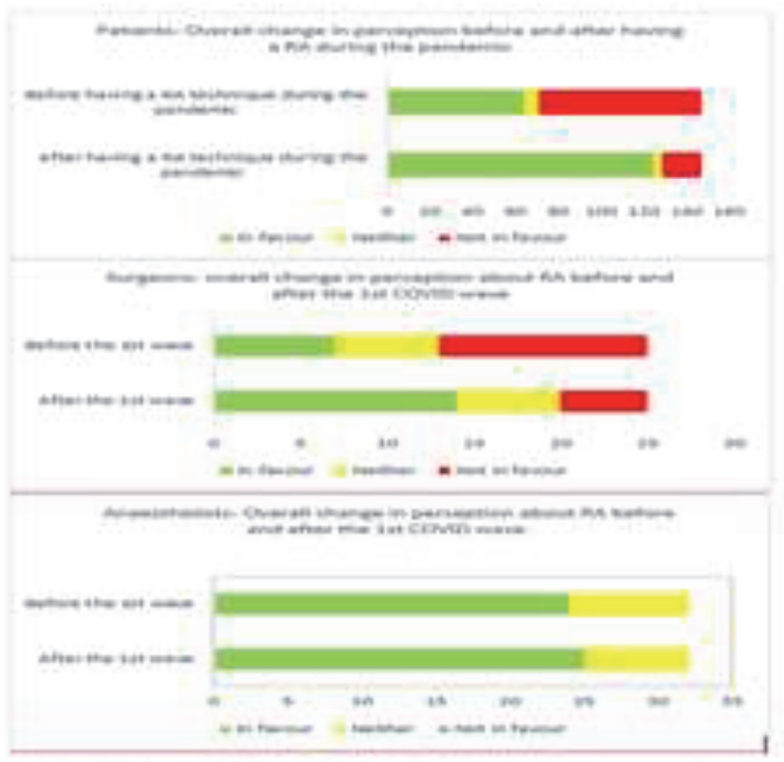

Abstract 91 Figure 3 Overall change before and after the first wave among patients, surgeons and anaesthetists

Conclusions Previous exposure to RA techniques increases the acceptance by patients and surgeons in the future. Anxiety about being awake/feeling pain among patients can be mitigated by reassurance and counselling during the preoperative visit. A focus on upskilling non-RA anaesthetists on high valuable Plan A blocks should be encouraged ${ }^{[1]}$ These points should be utilised to increase RA use after the pandemic as well.

\section{PATIENT WITH LOWE SYNDROME AND FANCONI TUBULOPATHY UNDERGOING SURGERY FOR SCOLIOSIS: ANAESTHETIC IMPLICATIONS AND FOCUS ON A SAFE PERIOPERATIVE MANAGEMENT OF A PLATELET DYSFUNCTION}

${ }^{1} \mathrm{M}$ Chami*, ${ }^{2} \mathrm{~N}$ Parisi. 'Université Catholique de Louvain/Cliniques Universitaires Saint LuC, Brussels, Belgium; ${ }^{2}$ Cliniques Saint Pierre Ottignies, Ottignies, Belgium

10.1136/rapm-2021-ESRA.92

Background and Aims Lowe syndrome or oculocerebrorenal syndrome is a rare X-linked multisystem disorder. It is characterised by bilateral cataract, severe hypotonia, mental retardation, stereotypic behaviour, as well as seizure disorders.

Patients also develop a proximal tubulopathy (Fanconi syndrome) which leads to proteinuria and renal tubular acidosis. Some patients may have an associated platelet dysfunction.

Only a few articles about Lowe Syndrome and anaesthesia exist in medical literature and only one case report regarding the perioperative anaesthetic management for a posterior spinal fusion surgery.

One of our aims was to describe the different challenges we had to overcome, and another was to include the patient in an ERAS (Enhanced Recovery After Surgery) program despite his pathology.

Methods We included the patient in our local fast-track scoliosis anaesthesia protocol. The latter includes an opioid-free total intravenous anaesthesia, with Dexmedetomidine, Propofol and Lidocaïne. It also includes a spinal anaesthesia with low dose intrathecal morphine.
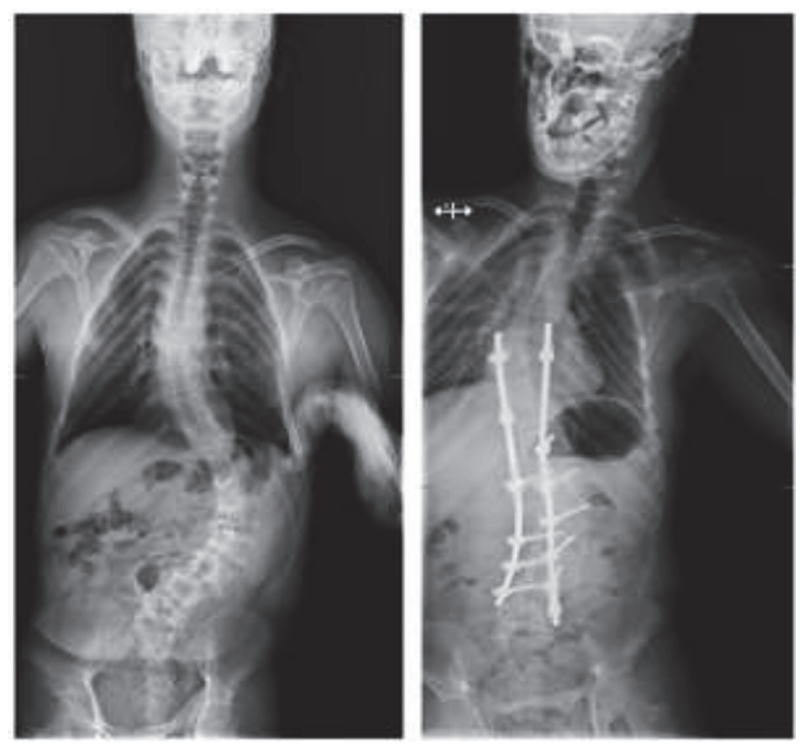

Abstract 92 Figure 1 Preoperative and Postoperative

\section{Abstract 92 Table 1}

\begin{tabular}{|l|l|c|c|c|c|}
\hline & Normal values & $09: 02$ & $14: 12$ & 16.39 & $23: 35$ \\
\hline Haemoglobin & $12-16 \mathrm{~g} / \mathrm{dL}$ & 8.2 & 7.5 & 7.6 & 7.6 \\
\hline pH & $7.35-7.45$ & 7.44 & 7.41 & 7.41 & 7.43 \\
\hline Bicarbonate & $22-28 \mathrm{mmol} / \mathrm{L}$ & 23 & 30 & 30 & 30 \\
\hline Lactacte & $0.5-1.6 \mathrm{mmol} / \mathrm{L}$ & 1.0 & 1.3 & 1.4 & 1.5 \\
\hline Potassium & $3.5-5.5 \mathrm{mmol} / \mathrm{L}$ & 3.1 & 3.4 & 3.4 & 3.9 \\
\hline
\end{tabular}

The patient's platelet function showed a reduced aggregation by $40-60 \%$ that we managed by administration of tranexamic acid, Desmopressin, and an intraoperative blood salvage machine. We also required a pool of platelets and two units of fresh frozen plasma during the surgery.

Results We managed to overcome the haemostatic and metabolic challenges, and managed to extubate the patient at the end of the surgery after analysing and verifying his biological, neurological, and respiratory statuses.

Conclusions We report a successful anaesthetic perioperative management of a 21 years old patient with Lowe syndrome scheduled for posterior spinal fusion for the treatment of scoliosis. 